\title{
PHYSIOTHERAPY MANAGEMENT STRATEGIES FOR WOMEN POST-CAESAREAN SECTION DELIVERY IN PUBLIC HOSPITALS IN KWAZULU-NATAL, SOUTH AFRICA
}

\begin{abstract}
South Africa has seen a steady increase in the rate of caesarean section deliveries, and while physiotherapists are often requested to treat these patients, there are no guidelines on their physiotherapeutic management. Current treatment is therefore based on clinical presentations of the patient. This paper reports on the physiotherapy management strategies for women post-caesarean section delivery used at four public hospitals in KwaZulu-Natal during 2011-2012. The study used a quantitative, cross-sectional, descriptive design. The sample consisted of 31 physiotherapists who completed an anonymous self-administered questionnaire, of whom eight had not treated post-caesarean section delivery women at all in the one year period. The results showed mobilization (100\%), breathing exercises (94\%) and education (94\%) were common choices, with $68 \%$ selecting pelvic floor exercises as part of their management strategy. The study concluded that the current physiotherapy management strategy for women post-caesarean section delivery is based mainly on the doctors' referral. Due to their limited knowledge about physiotherapy treatment, doctors overlook other complication(s) and potential complication(s) that could benefit from treatment post-delivery. The study showed that there is a need to improve the role and influence of physiotherapists in the multidisciplinary team.
\end{abstract}

KEY WORDS: PHYSIOTHERAPY MANAGEMENT, PHYSIOTHERAPY TREATMENT, CAESAREAN SECTION DELIVERY, SOUTH AFRICA, KWAZULU-NATAL.

\section{INTRODUCTION}

Physiotherapy has been involved in women's health since the early $19^{\text {th }}$ century (Mantle et al, 2006). While they were initially mainly involved with obstetric work, this gradually changed, and in the 1970s, physiotherapists also began to treat patients with gynaecological problems. (Mantle et al, 2006).

\section{Correspondence Author:}

Preshani Reddy

College of Health Sciences

Westville Campus

University of KwaZulu Natal,

Faculty of Health Science

South Africa

Email: reddypr@ukzn.ac.za
Today, physiotherapists play an essential role in the multidisciplinary treatment team, and treat a wide variety of obstetric and gynaecological issues. In this capacity, they are required to keep abreast with the latest medical techniques and associated complications.

Caesarean section delivery (CSD) has become one of the most common surgical procedures performed by obstetricians (Penna and Arulkumaran, 2003). In 1989, the World Health Organization (WHO) stated that caesarean section rates should account for between 10-15\% of births. Betrán et al (2007) reported that the global CSD rate was $15 \%$, with higher rates found in developed countries $(21.1 \%)$ compared to developing countries (2\%). In Africa, South Africa has the highest CSD rates (Betrán et al, 2007), with an average of $16.1 \%$ in
2008/09 (Health Systems Trust, 2009). Provincially, KwaZulu-Natal has the highest CSD rates amongst district hospitals in the country at $22.1 \%$ (Health Systems Trust, 2009). An audit done by Naidoo and Moodley (2009) on a specialist private practice within KwaZuluNatal found that maternal requests, breech delivery, HIV and previous CSD contributed to the high CSD rates in that particular practice. Literature has further cited that fear of vaginal delivery, the need for control in the birthing process (Lavender et al, 2012; Dhai et al, 2011), convenience, and the preservation of the pelvic floor (Dhai et al, 2011) are some of the reasons why women opt for a CSD. Although CSD are considered relatively safe (Dhai et al, 2011), there are still a number of complications associated with this procedure. 
The rate of complications following CSDs has been reported at $36 \%$, regardless of the type of CSD (van Ham et al, 1997). Complications include: sepsis, thromboembolic problems, anaesthetic complications (Koroukian, 2004), an increased rate of maternal morbidity (Kuklina et al, 2009) and pneumonia (Belfort et al, 2010). Conflicting evidence is presented in the literature as to whether a CSD can prevent pelvic floor trauma when compared to a normal vaginal delivery. Literature has suggested that the incidence of urinary stress incontinence following a CSD may be reduced if the procedure is performed prior to the onset of labor (Chin et al, 2005). However, it is still evident that a significant number of women experience urinary stress incontinence following a CSD (Chin et al., 2005). Pregnancy is more significant than vaginal delivery as a factor for permanent urinary incontinence (Faundes et al, 2001) and is largely attributed to the increased mechanical compression placed on the pelvic floor area during pregnancy (Faunders et al, 2001; Mant et al, 2009).

A problem that is often unreported and untreated in pregnant women is lower back pain (Wang et al, 2004; Morgren and Pohjanen, 2005). While the pathophysiology and etiology of lower back pain in pregnancy is poorly understood (Morgren and Pohjanen, 2005), contributing factors highlighted in the literature are an increase in weight (To and Wong, 2003), and an increase in joint mobility due to hormonal changes (Marnach et al, 2003). In terms of lower back pain and the use of epidural anesthesia, the literature indicates that immediate post-operative back pain was prevalent in patients, but that this was significantly reduced over time, with no difference found after a year between patients who had received epidural analgesia and patients who had not (Macarthur et al, 1997). What is noteworthy is a review by MacEvilly and Buggy (1996), which stated that the type of anaesesthia injected into the epidural space is also relevant in causing lower back pain.

Physiotherapists are well equipped to address these complications and prevent the onset of new ones with the use of manual therapy, exercise and/or electrotherapeutic modalities. However, there is currently no literature available on the physiotherapeutic management of women post-CSD, with the treatment techniques used being primarily based on patient presentation and clinical reasoning. This lack of research means that complication(s) or potential complication(s) post-CSD can therefore potentially not be addressed using best-practice methods. As there are no standardized physiotherapy management strategies for post-CSD complications used in South African hospitals, this study aimed to identify the management strategies used by physiotherapists to treat women post-CSD in four public hospitals in KwaZulu-Natal during 20112012. The objectives of the study were: (1) to identify the demographic profile of physiotherapists (2) to identify the physiotherapy management strategies of women post-CSD; (3) to identify the complications currently being addressed by physiotherapists in women postCSD, (4) to determine referral to other members of the multidisciplinary team by the physiotherapists and the advice given to the women on discharge.

\section{METHODS}

The study utilized a quantitative, crosssectional, descriptive survey design to determine the current management strategies employed by physiotherapists in the treatment of women post-CSD. It was conducted in 2012 at four public hospitals in KwaZulu-Natal using purposive sampling. The hospitals were selected on the basis that they were tertiary and/or regional hospitals, had a high obstetric and gynaecological patient turnover, and serviced a wide range of areas within the province. The study population consisted of all physiotherapists $(\mathrm{N}=37)$ employed by the respective hospitals.

A self-administered, anonymous questionnaire was developed based on available literature (Mantle et al, 2006; Pasquina et al, 2006; Hay-Smith et al, 2009). The survey questionnaire was divided into four sections to address the study objectives; Section A: demographic details of the participants, Section B: the number of patients post-
CSD treated and reasons for not treating patients, Section C: physiotherapy management post-CSD and Section D: referral to members of the multidisciplinary team and discharge advice. Section $\mathrm{C}$ identified the management of patients' post-CSD or the strategies that would have been used by those participants who had treated a post-CSD patient in 2011-2012.

A pilot study was conducted to determine the validity and reliability for the questionnaire, with experts $(\mathrm{N}=5)$ in the area of women's health being asked to review the questionnaire for content validity, after which minor changes were made. A focus group discussion was then done with physiotherapists not included in the study sample, for face validity and no problems were noted. Finally, the reliability of the study using the test-retest method was conducted among another group of physiotherapists $(\mathrm{N}=15)$ who were not included in the study. Repeatability analysis was undertaken using McNemar test between the same questions at pre- and post-test stage. No statistical difference $(p=1.00)$ was noted between the responses preand post-test.

As part of a $\mathrm{PhD}$ study, ethical approval (project number: 11/8/11) was obtained from the University of Western Cape Ethics Committee and the necessary documentation was sent to the respective hospitals within KwaZuluNatal. Permission to conduct the study was obtained from all the relevant facility managers, the eThekwini District office and the Provincial Department of Health. Once permission was obtained, final arrangements were made with the Physiotherapy Departments at the hospitals to conduct the study. All participants signed an informed consent form prior to participating in the study, and the consent form was detachable from the questionnaire to retain anonymity. The participants were allowed to withdraw at any stage. Completed questionnaires were captured on Microsoft Excel and exported to SPSS version 15 where the data was analyzed. Descriptive data analysis was then carried out for each section of the survey. Fisher's exact test was used to test for significance between categorical data; $\mathrm{CI}=95 \%$. 


\section{RESULTS}

A response rate of $84 \%(\mathrm{~N}=31)$ was achieved, and the mean age of the participants was 32 years $(\mathrm{SD} \pm 4.65)$. There were more females $(n=28)$ than males $(n=3)$. Of the participants, $45 \%$ $(n=14)$ had 3-7 years of experience, $26 \%(n=8)$ had $8-12$ years of experience and $29 \%(n=9)$ had 13-19 years of experience in Physiotherapy. In terms of post-graduate education, 96.7\% $(\mathrm{n}=30)$ do not have any post-graduate degree(s) in Physiotherapy.

Of the 31 participants, $68 \%(n=21)$ had treated post-CSD patients, $6 \% \quad(n=2)$ were unsure if they had treated postCSD patients and 26\% ( $n=8)$ had not treated post-CSD patients in 2011-2012. The self-reported number of patients treated following CSD by the participants varied, with a median of five and an interquartile rage of $0-15$. The most common reason reported by the participants for not having treated a CSD patient in the past year was that they had not been on an obstetric and gynaecology rotation $(29 \%$; $=9)$; other reasons are presented in Figure 1.

The mean number of physiotherapy treatment sessions rendered for each patient was 3.52 ( $\mathrm{SD} \pm 1.09)$, with the average treatment time being 15-30 minutes $(67.7 \% ; n=21)$. The year of undergraduate completion did not affect the average time spent treating a patient post-CSD ( $\mathrm{p}=0.35)$. The average treatment time spent with a patient was also similar, irrespective of whether or not the participant treated a patient post-CSD $(p=0.38)$ in 2011-2012. Various modalities were selected by physiotherapists for treating patients' post-CSD. All of the participants $(\mathrm{N}=31)$ selected mobilization as a treatment technique for post-CSD patients. For this study, the term mobilization is defined as "the process of re-establishing the ability to move between postures (for example sit to stand), maintain an upright posture, and to ambulate with increasing levels of complexity (speed, changes of direction, dual and multi-tasking)" as per the NICE clinical guideline124 (2011). Other modalities selected are described in Figure 2.

Treatment modalities selected by the participants were similar regardless of

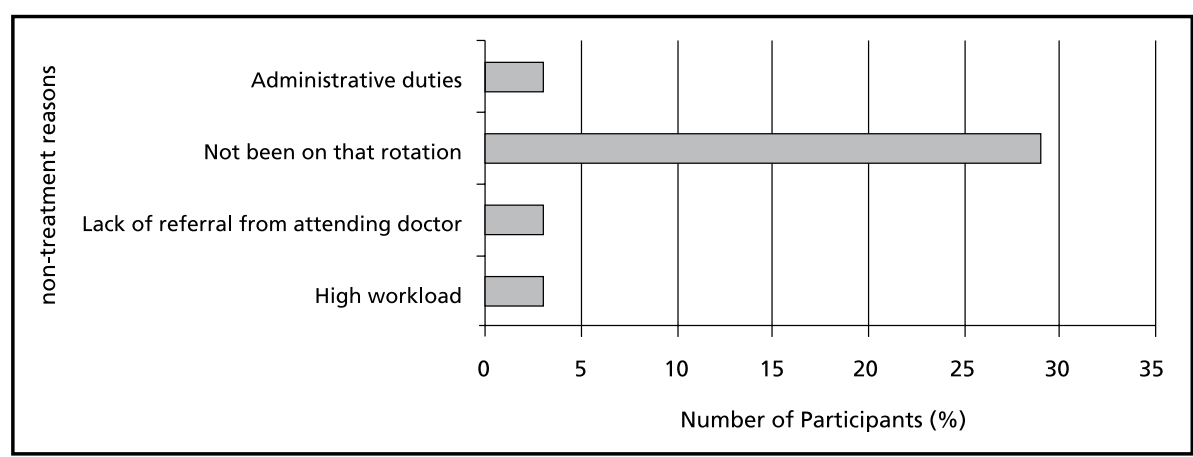

Figure 1: Reasons for not treating patients post-CSD

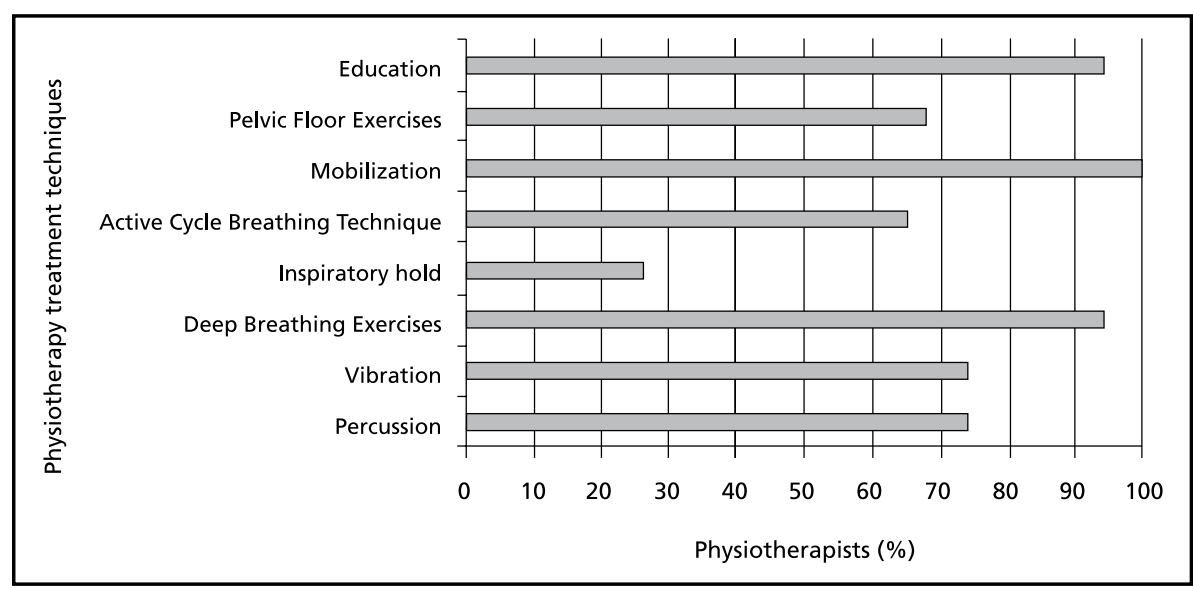

Figure 2: Choice of physiotherapy treatment techniques for patients post-CSD

Table 1: Modality selection vs year of graduation and treatment of women postCSD

\begin{tabular}{|l|l|l|}
\hline Modality Selection & $\begin{array}{l}\text { Year of } \\
\text { graduation }\end{array}$ & $\begin{array}{l}\text { Have you treated } \\
\text { a patient post-CSD }\end{array}$ \\
\hline Percussion & $p=0.80$ & $p=0.01$ \\
\hline Vibration & $p=0.80$ & $p=0.10$ \\
\hline Deep Breathing Exercises & $p=0.29$ & $p=0.48$ \\
\hline Inspiratory Hold & $p=0.76$ & $p=0.63$ \\
\hline Active Cycle Breathing Technique & $p=0.43$ & $p=0.10$ \\
\hline Pelvic Floor Exercises & $p=0.10$ & $p=0.48$ \\
\hline Education & $p=0.13$ & $p=0.17$ \\
\hline
\end{tabular}

\section{Two-tailed Fisher's exact test}

when the participants graduated (Table 1). Percussion was the only modality selected most frequently $(\mathrm{p}=0.01)$ as a treatment choice by those who had treated post-CSD patients in the past year compared to those who had not (Table 1).

Other techniques reported by the participants included; "circulatory exercises and breathing exercises" $(\mathrm{n}=1)$, "coughing techniques" $(\mathrm{n}=1)$ and "infrared lamp for post caesarean section hematoma" $(n=1)$.

Forty five percent $(n=14)$ of physiotherapists mentioned that they treated other complications following caesarean section and are shown in Figure 3.

Of the 31 participants who had and had not treated post-CSD patients in the past year, $19.4 \%(n=6)$ referred them to 


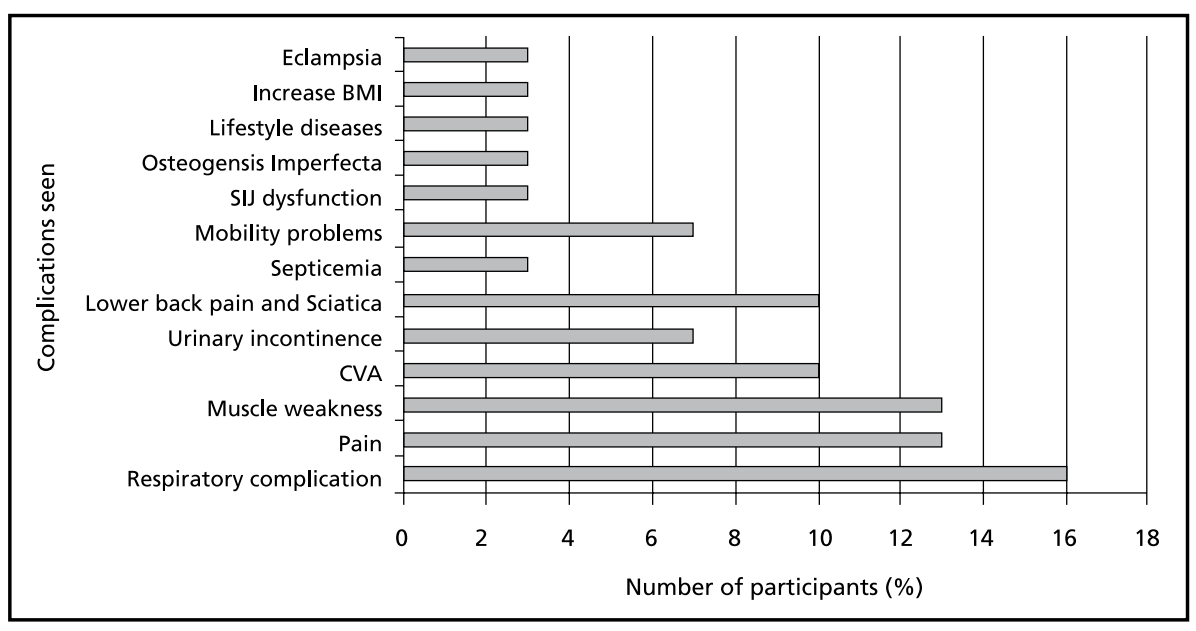

Figure 3: Complications seen by Physiotherapists

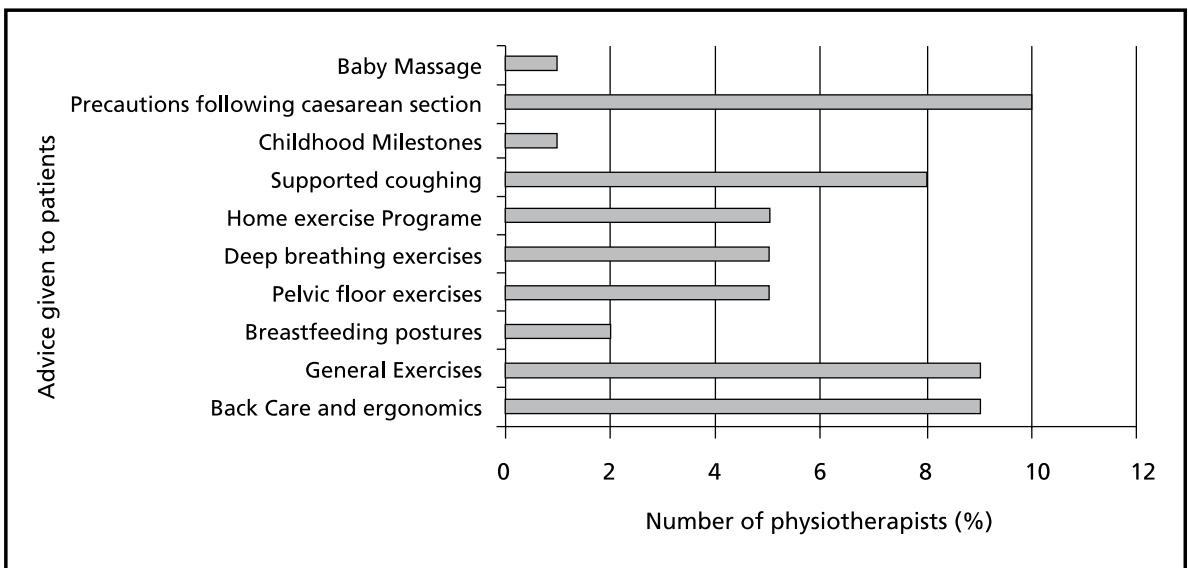

Figure 4: Discharge advice given to women post-CSD

other members of the multidisciplinary team including a clinical psychologist $(\mathrm{n}=1)$, social worker $(\mathrm{n}=1)$, dietician $(\mathrm{n}=1)$, doctor $(\mathrm{n}=1)$ and occupational therapist $(\mathrm{n}=2)$. Advice on discharge was given by $90.3 \%(n=28)$ of participants, and is indicated in Figure 4.

\section{DISCUSSION}

The results from the study suggest that the current physiotherapy management strategy for women post-CSD is based mainly on the doctors' referral, as doctors are only referring post-CSD patients who they deem necessary for physiotherapy. Therefore, other complications and potential complication as a result of the CSD procedure that should be identified by physiotherapists are not always addressed.

The physiotherapy management strategies selected for patients' post-CSD were similar, irrespective of the year of qualification and whether participants had treated patients post-CSD or not during the previous year (Table 1). It can therefore be concluded that physiotherapists are not modifying their management strategies to meet the specialized needs of post-CSD patients, but are using standard treatment routines. This may be due to the fact that none of the participants had received any specialized post-graduate training in post-CSD management. It suggests that physiotherapists depend on their undergraduate knowledge and have not changed their management strategies to include recent evidence based research. Globally, physiotherapists are required to keep abreast with new information and incorporate evidence based research into their clinical practice (French and Dowds, 2008). The results of this study are similar to a review by Schreiber and Stern (2005), which suggested that physiotherapy management was not based on research, but rather on anecdotal and undergraduate information. Furthermore, a study by Stevenson and
Lewis (2004) showed that although physiotherapists were in favour of evidence based research, they were reluctant to change their practice.

Anecdotal information from the hospitals used in this study indicates that some perform over 2000 caesarean sections per annum out of a total of 8400 births. With the study by van Ham et al, (1997) indicating that $36 \%$ of CSD women have complications and could require physiotherapy treatment, the low mean number of patients (mean $=5$ ) being treated by the participants demonstrates a low level of referral from obstetricians. There is evidence that physiotherapy can successfully treat postpartum problems post-CSD such as pelvic floor dysfunction and lower back pain (Britnell et al, 2005), and that in-hospital prophylactic treatment should also be rendered. What is noteworthy is the main reason selected for not having treated a patient post-CSD was not having been on that particular clinical rotation, with only one participant selecting "lack of referral from a doctor" (Figure 1). This indicates that obstetricians and gynaecologists are only referring patients who they deem necessary for physiotherapy. This is supported in the study by the mean number $\quad(m e a n=3.52 ; \quad \mathrm{SD}= \pm 1.09) \quad$ of treatment sessions rendered for a patient post-CSD. This is a high number of physiotherapy treatment sessions for uncomplicated post-CSD patients, as they are considered for discharge on day three post-operatively (South African Department of Health, 2007). Thus, the other reason for non-referral could be that uncomplicated post-CSD patients who would benefit from prophylactic treatment are not being referred for physiotherapy because doctors are unaware of the services physiotherapists render.

Participants in this study selected respiratory modalities (Figure 2) as part of their management strategy for patients' post-CSD. Although there is minimal evidence in the literature reporting on respiratory complications following an uncomplicated pfannenstiel incision for a caesarean section, participants stated that respiratory complications (16\%) was one of the main problems they 
addressed (Figure 3). This was followed by pain $(13 \%)$ and muscle weakness $(13 \%)$, while three participants mentioned lower back pain and sciatica, and two mentioned treating urinary incontinence as an added complication. The results suggest that obstetricians and gynaecologists at these hospitals mainly refer patients with respiratory complications for physiotherapy, indicating misconceptions regarding the services rendered by physiotherapists for patients' post-CSD. This is despite the role and influence of physiotherapy in obstetric and gynaecological conditions being established more than five decades ago (Mantle et al, 2006) Freeman et al, (2000) advised that in order for patients to be referred to other members of the multidisciplinary team, health care professionals need to understand each other's role and contribution towards patient care. Participants in this study indicated that they did refer patients to other members within the multidisciplinary team, with only one providing a reason for referral which was "to doctors, patient had severe abdominal pain - swab was left in the patient". This demonstrates the importance of communication and understanding each other's role when working as part of a team.

Advice on discharge was given to most of the patients, but only five $(16 \%)$ participants specified pelvic floor exercises and nine (29\%) specified back care and ergonomics as a home program. However, the literature indicates that in terms of potential problems following a CSD, urinary incontinence was prevalent (Chin et al., 2005) and lower back pain was frequently underreported (Wang et al, 2004; Morgren and Pohjanen, 2005). Studies have shown the benefit of a specific home exercise program for urinary incontinence (Haddow et al, 2005) and non-specific lower back pain (Kuukkanen et al, 2007) in post-CSD patients.

\section{CONCLUSION}

The Physiotherapy profession needs to educate obstetricians and gynaecologists about the role and effectiveness of physiotherapy techniques in patients' post-CSD. Scholes and Vaughan (2002) stated that inter-professional education is thought to improve collaboration between the members of the multidisciplinary team which will result in more effective and efficient team work. This could include inter-professional education workshops on the role of physiotherapy within the multidisciplinary team treating women post-CSD to increase referrals for treatment.

The lack of advice on pelvic floor and lower back exercises as prophylactic treatment in postpartum home programme(s) suggests a gap in awareness of the prevalence and types of complications that may arise post-CSD by the physiotherapists. Physiotherapy courses that provide additional training using evidence based practice management practices for CSD patients would enable practitioners to provide more appropriate treatment. More research by the physiotherapy profession is also needed to identify the standard physio therapy treatment needed by post-CSD women.

The study demonstrated the need for improvements in the role, effectiveness and influence of physiotherapists in their management strategy of postCSD patients. Greater awareness by the referring clinicians of the conditions that physiotherapists can treat post-CSD will not only strengthening their role within the multidisciplinary team, but assist more women who would benefit from additional treatment.

\section{ACKNOWLEDGEMENTS}

The authors would like to thank the South African Society of Physiotherapy for their support and Professor R.Mpofu for her valuable input.

\section{REFERENCES}

Belfort M, Clark S, Saade G, Kleja K, Dildy G III, Van VeenTR,Akhigbe E, Frye DR, Meyers JA, Kofford S (2010) Hospital readmission after delivery: evidence for an increased incidence of non-urogenital infection in the immediate postpartum period. American Journal of Obstetrics and Gynecology. 202(1): 35e1- 35e7.

Betrán A P, Merialdi M, Lauer JA, Bing-shun W, Thomas J, Look PV, Wagner L (2007) Rates of caesarean section: analysis of global, regional and national estimates. Paediatric and Perinatal Epidemiology.21: 98-113.

Britnell SJ, Cole JV, Isherwood L, Sran MM, Britnell N, BurgiS,Candido G, Watson L (2005) Postural Health in Women: the role of Physiotherapy. Journal of Obstetrics and Gynaecology Canada.27(5): 493-500.

Chin H-yen, Chen M-C, Liu H-yen, Wang K-hwa (2006) Postpartum urinary incontinence: a comparison of vaginal delivery, elective, and emergent cesarean section. Journal of Obstetrics and Gynaecology.17: 631-635.

Dhai A, Gardner J, Guidozzi Y, Howarth G, Vorster M (2011) Vaginal deliveries - is there a need for documented consent? South African Medical Journal.101(1): 20-22.

Faundes A, Guarisi T, Pinto-Neto AM (2001) The risk of urinary incontinence of parous women who delivered only by cesarean section. International Journal of Gynecology and Obstetrics. 72(1): 41-46.

Freeman M, Miller C,Ross N (2000) The impact of individual philosophies of team working on multiprofessional practice and the implications for education. Journal of International Professional Care. 14 (3): 237-247.

French HP, Dowds J (2008) An overview of Continuing Professional Development in physiotherapy. Physiotherapy.94: 190-197.

Haddow G, Watts R, Robertson J (2005) Effectiveness of a pelvic floor muscle exercise program on urinary incontinence following childbirth. International Journal of Evidence Based Healthcare.3: 103-146.

Hay-Smith J, MørkvedS,Fairbrother KA, Herbison GP (2008) Pelvic floor muscle training for prevention and treatment of urinary and faecal incontinence in antenatal and postnatal women. Cochrane Database of Systematic Reviews. 4

Health Systems Trust (2009) The District Health Barometer 2008/09. Health Systems Trust. Durban. 
Koroukian SM (2004) Relative risk of postpartum complications in the Ohio medicaid population: vaginal versus cesarean delivery. Medical Care Research and Review. 61(2):203-224.

Kuklina E, Meikle S, Jamieson D, Whiteman M, Barfield W, Hillis S, Posner S (2009) Severe obstetric morbidity in the United States: 19852005. Obstetrics \& Gynecology. 113: 293-299.

Kuukkanen T, Malkia E, Kautiainen $\mathrm{H}$, Pohjolainen T (2007) Effectiveness of a home exercise programme in low back pain: a randomized five year follow-up study. Physiotherapy Research International. 12(4):213-224.

Lavender T, Hofmeyr GJ, Neilson JP, Kingdon C, Gyte GML (2012) Caesarean section for nonmedical reasons at term. Cochrane Database of Systematic Reviews. 3.

Macarthur AJ, Macarthur C, Weeks SK (1997) Is Epidural Anesthesia in labor Associated with Chronic Low Back Pain? A Prospective Cohort Study.Anesthesia and Analgesia.85: 1066-1070.

MacEvillyM, Buggy D(1996) Review Article Back pain and pregnancy: a review. Pain.64: 405-414.

Mandy A, Milton C, Mandy P (2004) Professional stereotyping and interprofessional education. Learning in Health and Social Care.3(3): 154-170.

Mant J, Painter R, Vessey M (1997) Epidemiology of genital prolapse: observations from the Oxford Family Planning Association Study.
British Journal of Obstetrics and Gynaecology. 104(5):579-585.

Mantle M, Haslam J, Barton S (2006). Physiotherapy in Obstetrics and Gynaecology, $2^{\text {nd }}$ edn. Britain, Butterworth-Heinemann.

Marnach ML, Ramin KD, Ramsey PS, Song S-whan, Stensland JJ, An K-nan (2003) Characterization of the relationship between joint laxity and maternal hormones in pregnancy. The American College of Obstetricians and Gynecologists.101(2): 331-335.

Mogren IM, Pohjanen AI (2005) Low Back Pain and Pelvic Pain During Pregnancy Prevalence and Risk Factors. Spine.30(8): 983-991.

Naidoo N, Moodley J (2009) Rising rates of Caesarean sections: an audit of Caesarean sections in a specialist private practice. South Africa Family Practice.51(3): 254-258.

NICE Clinical Guideline 124 (2011) Hip Fracture: The management of hip fracture in adults. National Clinical Guideline Centre, National Institute for Health and Clinical Excellence.

Pasquina P, Tramèr MR, Granier JM, Walder B (2006) Respiratory physiotherapy to prevent pulmonary complications after abdominal surgery: a systematic review. Chest.130(6): 1887-99.

Penna L, Arulkumaran S (2003) Cesarean section for non-medical reasons. International Journal of Gynecology and Obstetrics. 82:399-409
Scholes J, Vaughan B (2002) Cross-boundary working: implications for the multiprofessional team. Journal of Clinical Nursing. 11: 399-408

Schreiber J, Stern P (2005) A Review of the Literature on Evidence-Based Practice in Physical Therapy. The Internet Journal of Allied Health Sciences and Practice.3(4): 1-10

South African Department of Health. (2007). Guidelines for maternity care in South Africa: A manual for clinics, community health centers and district hospitals, $3^{\text {rd }}$ edn. Republic of South Africa, Department of Health

To WWK, Wong MWN (2003) Factors associated with back pain symptoms in pregnancy and the persistence of pain 2 years after pregnancyActaObstetriciaetGynecologicaScandinavica. 82:1086-1091.

Van Ham M, Van Dongen P, Mulder J (1997) Maternal consequences of cesarean section: a retrospective study of intra-operative maternal complications of cesarean section during a 10-year period. European Journal of Obstetrics \& Gynecology and Reproductive Biology, 74 (1), 1-6.

Wang S-Ming, Dezinno P, Maranets I, Berman MR, Caldwell-Andrews AA, Kain ZN (2004) Low Back Pain During Pregnancy: Prevalence, Risk Factors, and Outcomes. American College of Obstetricians and Gynecologists.104(1): 65-70. 